\title{
STUDI KINETIKA DEHIDRASI RISINOLEAT DARI MINYAK JARAK
}

\author{
M. Sitorus ${ }^{1}$, S. Ibrahim ${ }^{2}$, H. Nurdin ${ }^{2}$ and D. Darwis ${ }^{2}$ \\ ${ }^{1}$ Laboratorium Kimia Organik FMIPA UNIMED Medan; Program $S_{3}$ PPS UNAND Padang. \\ ${ }^{2}$ Laboratorium Kimia Organik Sintesis FMIPA UNAND Padang. \\ email: marham.sitorus@gmail.com
}

\begin{abstract}
Dehydration of ricinoleic of castor oil into mixed of linoleic acid (LA) and conjugated linoleic acid (CLA) named DCO (dehydrated Castor Oil) was conducted by using $\mathrm{P}_{2} \mathrm{O}_{5}$ at temperature $125^{\circ} \mathrm{C}$ and $175^{\circ} \mathrm{C}$ were held time variety at $1,2,3$ and 4 hour. Dehydration was maintained under reduced pressure 50 to $70 \mathrm{mmHg}$, gentle bubbling with Nitrogen, magnetically stirred between 800 to 1000 rpm and $0.1 \mathrm{~g} \mathrm{Zn} \mathrm{powder} \mathrm{as} \mathrm{antipolymerization} \mathrm{agent.} \mathrm{The} \mathrm{concentration} \mathrm{changes} \mathrm{of} \mathrm{the} \mathrm{ricinoleic}$ and DCO followed by contrentation GC. The elucidation of ricinoleic, LA and CLA were analyzed by GC-MS. The result showed that reaction was first order with rate constant (k) was $1.0 \times 10^{-2} \mathrm{~h}^{-1}$ at $125^{\circ} \mathrm{C}$ and $0.9631 \mathrm{~h}^{-1}$ at $175^{\circ} \mathrm{C}$ and energy of activation (Ea) was $191.152 \mathrm{kJmol}^{-1}$ and
\end{abstract}

Keywords: Dehydration, Kinetic, Ricinoleic, LA and CLA.

\section{PENDAHULUAN}

Reaksi senyawa organik pada umumnya berlangsung relatif lambat dibanding dengan reaksi-reaksi senyawa anorganik pada umumnya. Reaksi kimia dapat ditinjau berdasarkan kontrol termodinamika yaitu berdasarkan energi bebas Gibbs $(\Delta G)$ yang menyatakan reaksi akan berlangsung spontan apabila $\Delta \mathrm{G}<0$, dimana bila energi bebas makin kecil maka reaksi makin spontan ${ }^{[1]}$. Aspek termodinamika tidak dapat digunakan sebagai acuan untuk memperkirakan kecepatan reaksi.

Kecepatan atau laju reaksi dapat diperkirakan berdasarkan kontrol kinetika yaitu berdasarkan harga orde atau tingkat reaksi yang menentukan harga konstanta kecepatan reaksi (k) dan energi aktivasi (Ea). Reaksi akan makin cepat apabila $\mathrm{k}$ makin besar atau $\mathrm{Ea}$ makin kecil. Selanjutnya berdasarkan orde, $\mathrm{k}$ dan Ea maka mekanisme atau jejak suatu reaksi dapat ditentukan. Dengan mengetahui mekanisme suatu reaksi, maka reaksi dapat diarahkan untuk menghasilkan suatu produk selektif yang diinginkan berdasarkan manipulasi harga $\mathrm{k}$ dan $\mathrm{Ea}$, karena pada umumnya reaksi molekul organik merupakan produk campuran ${ }^{[2]}$, dan dalam skala industri akan menjadi pedoman untuk mendesain reaktor yang sesuai dengan reaksi yang dilakukan $^{[3]}$.

Reaksi dehidrasi merupakan jenis reaksi eliminasi yaitu pengurangan molekul air $\left(\mathrm{H}_{2} \mathrm{O}\right)$ dari suatu molekul alkohol (mengandung gugus $-\mathrm{OH}$ ) yang bertetangga dengan suatu Ho. Reaksi dehidrasi sudah sangat umum dilakukan namun untuk molekul besar dan multi gugus fungsional seperti dehidrasi risinoleat maka dehidratornya harus spesifik untuk mencegah berbagai reaksi samping dari dua gugus lain yaitu alkena $(\mathrm{C}=\mathrm{C})$ dan triester ${ }^{[4,5]}$.

Dehidrasi risinoleat menghasilkan minyak jarak terdehidrasi $(\mathrm{DCO}=$ dehydrated castor oil) yaitu campuran antara linoleat (LA) [18:2 $(9,12)]$ dan linoleat terkonjugasi (CLA = conjugated linoleic acid ) $[18: 2(9,11)]$ karena terdapat dua $\mathrm{H} \alpha$ terhadap alkohol. Risinoleat mempunyai nama kimia 12-hidroksi-9-cis enoat dengan notasi [18: 1 (9), $12(-\mathrm{OH})]$. Persamaan reaksi dehidrasi risinoleat dalam bentuk asam lemaknya adalah seperti yang terlihat pada Gambar 1. 
Dehidrasi terhadap risinoleat akan menghasilkan dua produk utama yaitu linoeat $(\mathrm{LA}=$ linoleic acid) dan linoleat terkonjugasi $(\mathrm{CLA}=$ conjugated linoleic acid $)$ sebagai produk dominan karena stabilisasi resonansi ${ }^{[6,7]}$.

Penelitian ini secara umum didasarkan pada penelitian-penelitian terdahulu yaitu studi kinetik isomerisasi eugenol ${ }^{[8]}$, studi kinetika isomerisasi $\alpha$-pinena ${ }^{[9]}$, isomerisasi terhadap trans anethole ${ }^{[10]}$ dan studi kinetika isomerisasi safrol ${ }^{[11]}$. Secara spesifik didasarkan pada hasil penelitian terdahulu yaitu studi kinetika dehidrasi $n$-butanol ${ }^{[12]}$, isomerisasi $\alpha$-pinena ${ }^{[13]}$ isomerisasi eugenol ${ }^{[2]}$ dan dehidrasi risinoleat $^{[4,5,14]}$. Studi kinetika terhadap reaksi dehidrasi risinoleat akan mendapatkan jejak reaksi yang dapat mengarahkan reaksi dan desain reaktor untuk memperoleh produk CLA sebagai produk yang lebih essensial secara maksimal. Pada penelitian ini data yang diperoleh adalah orde reaksi, konstanta (k) kecepatan reaksi dan energi aktivasi (Ea).

\section{METODOLOGI}

\section{Alat dan Bahan}

Peralatan yang digunakan adalah berbagai alat gelas, satu set alat refluks, alat GC HP 3890, dan alat GC-MS QP2010S Shimadzu.
Bahan yang digunakan antara lain: minyak jarak komersial, $\mathrm{P}_{2} \mathrm{O}_{5}$, logam natrium $(\mathrm{Na})$, metanol absolut, serbuk logam Zn, akuades dan kertas $\mathrm{pH}$ universal.

\section{Prosedur}

Penentuan Komposisi Minyak Jarak dan DCO

Sebanyak $15 \mathrm{~mL}$ minyak jarak komersil atau DCO dicampur dengan $50 \mathrm{~mL}$ Na metanol $1 \%$. Selanjutnya dilakukan refluks pada suhu sekitar $60^{\circ} \mathrm{C}$ sampai $90^{\circ} \mathrm{C}$ selama setengah jam. Hasil refluks didinginkan dan lapisan metil ester asam lemak (fatty acid methyl esthers = FAME) diambil dan dinetralkan dengan akuades yang dipantau dengan indikator $\mathrm{pH}$ universal. Setelah netral dikeringkan dengan $\mathrm{Na}_{2} \mathrm{SO}_{4}$ anhidrat dan komposisinya dianalisis dengan GC-MS.

\section{Studi Kinetika Dehidrasi Risinoleat}

Reaksi dehidrasi dilakukan pada aliran gas nitrogen, dengan tekanan berkisar antara 50 sampai $70 \mathrm{mmHg}$, kecepatan pengadukan berkisar antara 800 sampai $1000 \mathrm{rpm}$ dengan penambahan $0,1 \mathrm{~g}$ serbuk $\mathrm{Zn}$ sebagai anti polimerisasi variasi waktu reaksi $1,2,3$, dan 4 jam dengan jumlah dehidrator $2 \%(\mathrm{w} / \mathrm{w})$ pada suhu $125^{\circ} \mathrm{C}$ dan $175^{\circ} \mathrm{C}$.<smiles>CCCCCCCCC=CCC(=O)O</smiles>

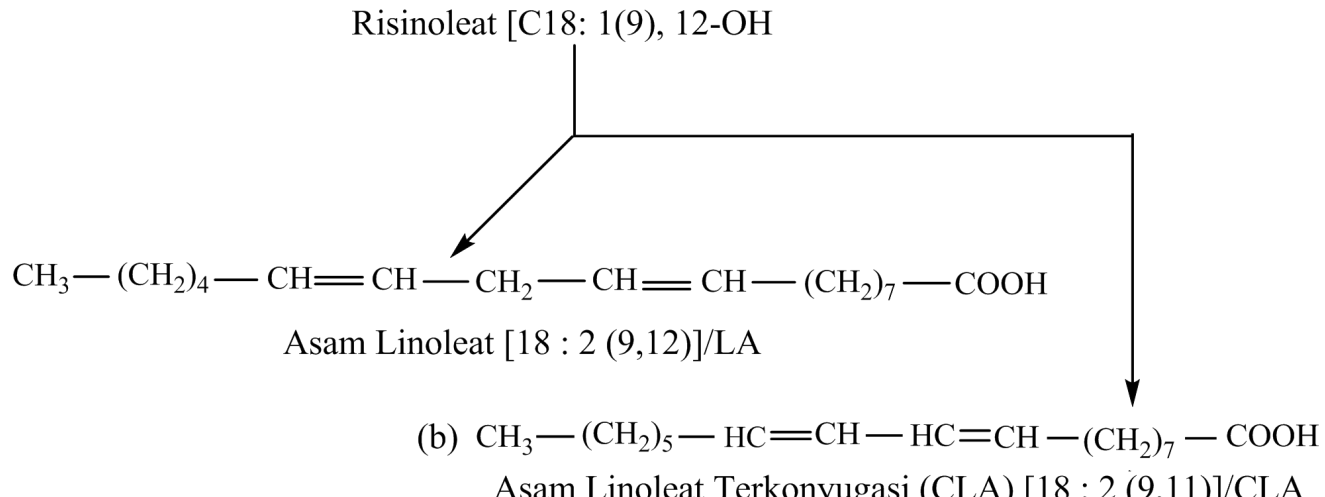

Asam Linoleat Terkonyugasi (CLA) $[18: 2(9,11)] / C L A$

Gambar 1. Persamaan reaksi dehidrasi risinoleat dalam bentuk asam lemaknya 
Penentuan orde reaksi adalah dengan membuat grafik orde 1 ( $L n C$ vs t), orde 2 ( $1 / \mathrm{C} \mathrm{Vs} \mathrm{t)} \mathrm{dan}$ orde $3\left(1 / \mathrm{C}^{2}\right.$ vs $\left.\mathrm{t}\right)$. Grafik yang paling linier dengan $\mathrm{R}^{2}$ paling mendekati satu adalah merupakan orde reaksi untuk dehidrasi pada $125^{\circ} \mathrm{C}$ dan $175^{\circ} \mathrm{C}$.

Penentuan Ea adalah dengan membandingkan dua data konstantan kecepatan reaksi $(\mathrm{k})$ pada $125^{\circ} \mathrm{C}$ dan $175^{\circ} \mathrm{C}$ dengan menggunakan persamaan Archenius .

\section{HASIL DAN PEMBAHASAN}

\section{Penetuan Orde Konstanta Kecepatan Reaksi dan Energi Aktivasi}

Minyak jarak yang digunakan adalah minyak jarak yang diperdagangkan (komersil) dengan komposisi komponennya berdasarkan data GCMS (kromatogram gambar 1) adalah 1,57\% palmitat; 5,64\% linoleat; 4,86\% 9oktadekanoat dan $85,26 \%$ risinoleat.

Persamaan reaksi dehidrasi risinoleat dengan $\mathrm{P}_{2} \mathrm{O}_{5}$ secara umum adalah:

Risinoleat (Ris) $+\mathrm{P}_{2} \mathrm{O}_{5} \longrightarrow \mathrm{CLA}+\mathrm{LA}$

Laju reaksinya adalah:

$-d[R i s] / d t=d[L A C L A] / d t=\mathrm{k}[\mathrm{Ris}]\left[\mathrm{P}_{2} \mathrm{O}_{5}\right]$

Hasil penelitian reaksi dehidrasi risinoleat dengan variasi waktu pada suhu $125^{\circ} \mathrm{C}$ dan $175^{\circ} \mathrm{C}$ adalah seperti tabel 1 .

Selanjutnya untuk menentukan orde reaksi maka diujikan grafik orde 1 ( $\operatorname{Ln} \mathrm{C}$ vs $\mathrm{t}$ ), orde 2 ( $1 / \mathrm{C}$ Vs $\mathrm{t})$ dan orde $3\left(1 / \mathrm{C}^{2}\right.$ vs $\left.\mathrm{t}\right)$. Berdasarkan uji pembuatan grafik maka diperoleh hasil harga linieritas $\left(\mathrm{R}^{2}\right)$ seperti tabel 2 berikut.

Hasil uji grafik persamaan orde reaksi menunjukan bahwa reaksi adalah orde 1 karena mempunyai linieritas paling besar (paling mendekati 1) yaitu 0,833 pada temperatur $125^{\circ} \mathrm{C}(398 \mathrm{~K})$ dan 0,9262 untuk temperatur $175^{\circ} \mathrm{C}(448 \mathrm{~K})$ dengan grafik seperti gambar 2 dan 3 .
Berdasarkan gambar 2 maka besar slope adalah $-0,01$ dan gambar 3 slope $-0,9631$ maka konstanta kecepatan reaksi $\mathrm{k}$ pada $125^{\circ} \mathrm{C}(398$ K) adalah $0,01 \mathrm{Jam}^{-1}$ dan pada suhu $175^{\circ} \mathrm{C}$ $(448 \mathrm{~K})$ adalah $0,9631 \mathrm{Jam}^{-1}$.

Perhitungan harga energi aktivasi dilakukan dengan membandingkan dua data $\mathrm{k}$ dengan menggunakan persamaan Arhenius:

$$
\mathrm{k}=\mathrm{e}^{-\mathrm{Ea} / \mathrm{RT}}
$$

Dengan membandingkan dua data $\mathrm{k}$ yaitu $\mathrm{k}$ pada $125^{\circ} \mathrm{C}(398 \mathrm{~K})$ dan $175^{\circ} \mathrm{C}(468 \mathrm{~K})$ maka diperoleh persamaan untuk menghitung $\mathrm{Ea}$ sebagai berikut:

$$
\ln \left(\mathrm{k}_{1} / \mathrm{k}_{2}\right)=-(\mathrm{Ea} / \mathrm{R}) \times\left\{\left(\mathrm{T}_{1}-\mathrm{T}_{2}\right) /\left(\mathrm{T}_{1} \times \mathrm{T}_{2}\right)\right.
$$

Dengan memasukkan harga $\mathrm{k}_{1}=0,01 \mathrm{Jam}^{-1}, \mathrm{k}_{2}$ $=0,963, \mathrm{~T}_{1}=398 \mathrm{~K}, \mathrm{~T}_{2}=448 \mathrm{~K}$ dan konstanta $\mathrm{R}=8,314 \mathrm{~J} \mathrm{~mol}^{-1} \mathrm{~K}^{-1}$ maka diperoleh harga energi aktivasi (Ea) sebesar 191,152 $\mathrm{kJ} \mathrm{mol}^{-1}$.

\section{Elusidasi Struktur Hasil Dehidrasi}

Hasil utama dari dehidrasi risinoleat adalah linoleat $(\mathrm{LA}=$ linoleic acid) dan linoleat terkonjugasi $(\mathrm{CLA}=$ conjugated linoleic acid) dengan produk dominan adalah CLA yang dapat mencapai $70 \%$, karena distabilkan oleh resonansi sesuai dengan hukum Zeithzev ${ }^{[6,7]}$. Disamping dua produk utama di atas maka reaksi samping juga umum terjadi pada reaksi senyawa organik. Beberapa reaksi samping dapat diproteksi atau diminimalisasi seperti pada dehidrasi risinoleat ini dengan menambahkan serbuk $\mathrm{Zn}$ sebagai anti polimerisasi alkena dan aliran gas nitrogen untuk mengusir oksigen sehingga mencegah oksidasi ikatan rangkap.

Temuan baru pada penelitian ini adalah mempelajari kinetika reaksi risinoleat secara in situ atau mereaksikannya secara langsung dalam bentuk minyak jarak (castor oil), tanpa memisahkannya terlebih dahulu. Komposisi risinoleat hasil dehidrasi $(\mathrm{DCO}=$ dehidrated castor oil) adalah 9,90\% LA dan CLA (C,C); $23,23 \%$ LA dan CLA (C,Z) yang merupakan isomer paling esensial; $6,01 \%$ LA dan CLA $(Z, Z), 20,09 \%$ sisa risinoleat, dan terbentuk 
$16,16 \%$ senyawa 8,11 -oktadekadienat yang juga suatu isomer linoleat ${ }^{[4,5,15]}$ dengan kromatogram seperti gambar 4 berikut.
Karena perubahan risinoleat tidak hanya menjadi LA dan CLA tapi juga senyawa 8, 11oktadekadienat sebanyak $16,16 \%$, maka studi kinetik kurang akurat bila dilakukan berdasarkan laju pertambahan produk.

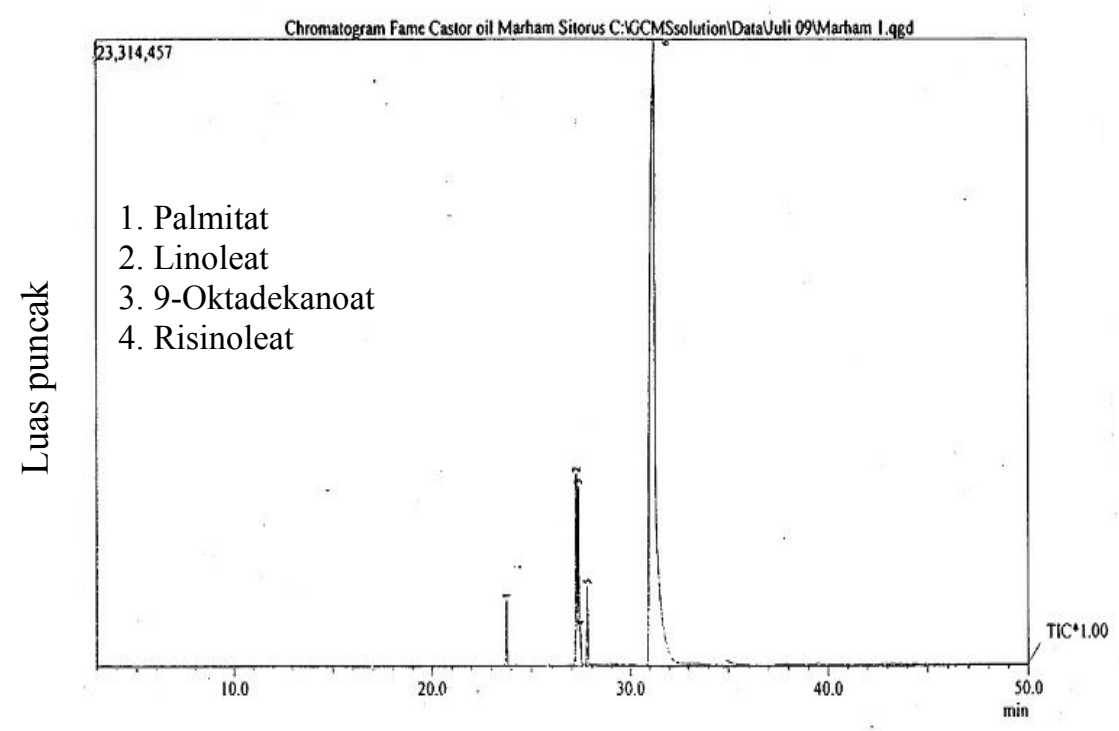

Waktu retensi

Gambar 1. Kromatogram GC-MS Minyak jarak

Tabel 1: Konsentrasi Risonoleat dengan Variasi Waktu

\begin{tabular}{ccc}
\hline \multirow{2}{*}{ Waktu (Jam) } & \multicolumn{2}{c}{$[\%$ Risinoleat $]$} \\
\cline { 2 - 3 } & Suhu $125^{\circ} \mathrm{C}$ & Suhu $175^{\circ} \mathrm{C}$ \\
\hline 1 & 77,52 & 61,67 \\
2 & 77,85 & 31,77 \\
3 & 76,90 & 17,48 \\
4 & 75,38 & 3,36 \\
\hline
\end{tabular}

Tabel 2: Hasil Linieritas Uji Orde Reaksi

\begin{tabular}{ccc}
\hline \multirow{2}{*}{ Uji orde reaksi } & \multicolumn{2}{c}{ Harga linieritas $\left(\mathrm{R}^{2}\right)$} \\
\cline { 2 - 3 } & $125^{\circ} \mathrm{C}$ & $175^{\circ} \mathrm{C}$ \\
\hline 1 & 0.8333 & 0,9262 \\
2 & 0,7353 & 0,7193 \\
3 & 0,7781 & 0,6273 \\
\hline
\end{tabular}




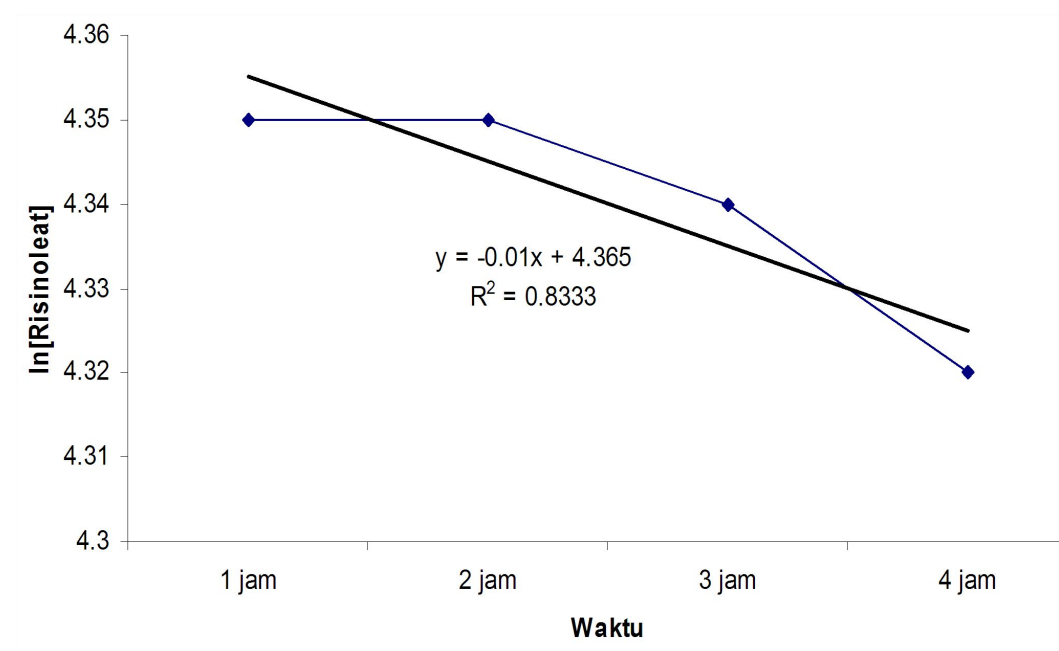

Gambar 2. Grafik $\ln$ [Risinoleat] vs Waktu $125^{\circ} \mathrm{C}$

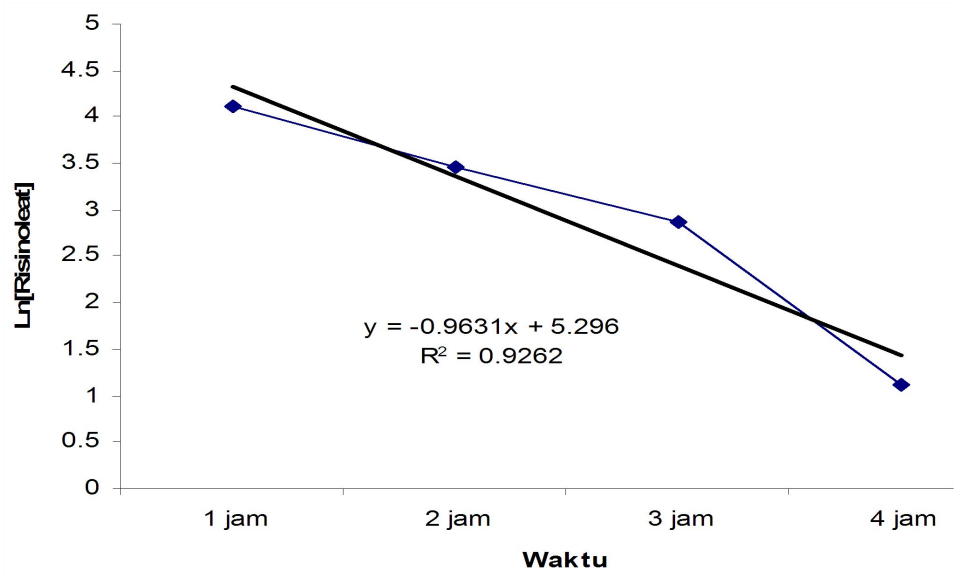

Gambar 3. Grafik ln [Risinoleat] vs Waktu $175^{\circ} \mathrm{C}$

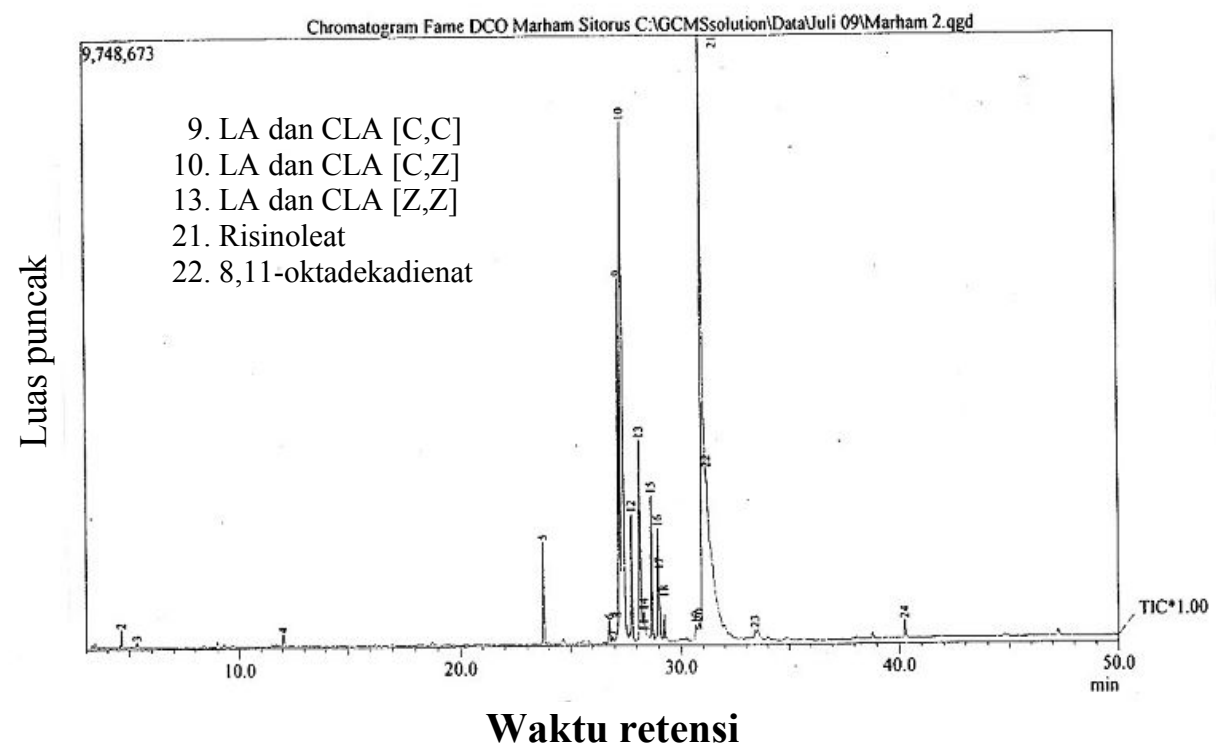

Gambar 4. Kromatogram GC-MS minyak jarak hasil dehidrasi (DCO) 


\section{KESIMPULAN}

Dehidrasi risinoleat menghasilkan dua produk utama linoleat terkonjugasi (CLA) dan linoleat (LA) yang berdasarkan data GC-MS masih bergabung karena keduanya merupakan isomer dengan perbedaan posisi ikatan rangkap sehingga mempunyai sifat fisik yang berdekatan. Reaksi dehidrasi risinoleat dilakukan dalam bentuk minyak jarak dengan hasil reaksi merupakan orde satu dengan konstanta kecepatan reaksi (k) pada $125^{\circ} \mathrm{C}$ $(398 \mathrm{~K})$ sebesar $0,01 \mathrm{Jam}^{-1}$ dan pada $175^{\circ} \mathrm{C}$ $(448 \mathrm{~K})$ sebesar $0,9631 \mathrm{Jam}^{-1}$. Energi aktivasi (Ea) yang dihitung dengan membandingkan dua data menggunakan persamaan Arhenius adalah sebesar 191,152 $\mathrm{kJ} \mathrm{mol}^{-1}$. Studi kinetika kurang akurat bila ditentukan berdasarkan pertambahan produk karena menghasilkan produk samping selain CLA dan LA.

\section{UCAPAN TERIMA KASIH}

Terima kasih kepada $\mathrm{DP}_{2} \mathrm{M}$ Direktorat Jenderal Pendidikan Tinggi (DIKTI) Departemen Pendidikan Nasional yang telah mendanai penelitian ini melalui proyek Penelitian Hibah Bersaing (HB) untuk Tahun Anggaran 2009/2010. Terima kasih juga disampaikan kepada Marida, Purnama, J. Purba, M. Sinaga dan M. Nizam atas kontribusinya pada penelitian untuk bahan tulisan ini.

\section{DAFTAR PUSTAKA}

1. M. Sitorus, Kimia Organik Fisik, Graha Ilmu, Yoyakarta, 2008.

2. A. Kadarohman, Isomerisasi Hidrogenasi Eugenol dan Sintesis Turunan Kariofiline Disertasi $\mathrm{S}_{3}$ Ilmu Kimia PPs UGM (Tidak diupblikasi),Yoyakarta, 2003.

3. Nurhayati dan Subagjo, Analisis Thermodinamika Dehidrasi n-butanol, Prosiding Seminar Nasional Fundamental Dan Aplikasi Teknik Kimia, (Surabaya, 24-25 Nopember 1999), 1999.

4. M. Sitorus, S. Ibrahim, H. Nurdin dan D. Darwis, Optimasi Kondisi Reaksi Pada
Pembuatan Minyak Jarak Terdehidrasi (DCO), Jurnal Sains Indonesia, Fakultas MIPA UNIMED, Medan, 33(1):51-56, (2009).

5. M. Sitorus, S. Ibrahim, H. Nurdin and D. Darwis, Transformation of Ricinoleic of Castor Oil Into Linoleic (Omega-6) and Conjugated Linoleic Acid, Indo. J. Chem., 9(2):278-284, (2009).

6. D. N. Bhowimick and A. N. Sarma, Dehydration of Castor Oil, Ind. Eng. Chem. Prod, Departement of Oil and Paint Technology, Kampur India, 1987.

7. W.G. Priest, J. D. Von Mikusch, Composition and Analysis of Dehydrated Castor Oil, Woburn Degreasing Company of New Jessey, New York, 1997.

8. H. P. Peterson, J. H. Bryan and T. A. Keevil, A Kinetic Study of The Isomerzation of Eugenol, J. Chem. Edu., 70(4):A96-A98), (1993).

9. A. I. Allahverdiev, G. Gunduz and D. Y. Murzin, Kinetics of Alpha-Pinene Isomerization, Ind. Eng. Chem. Res., 37: 2373-2377, (1998).

10. K. S. Sharma, V. K. Srivastava, P. H. Pandya and R. V. Jasra, Solvent-free Isomerization of Methyl Chavicol to transAnethole Using Transition Metal Complexes as Catalyst, Catalysis Communication, 6:205-209, (2005).

11. S. J. Sekewael, I. Telussa dan H. J. Sohilait, A Kinetic Study of The Isomerization of Safrol, Skripsi $\mathrm{S}_{1}$ Kimia FMIPA UNPATTI, Ambon, 2006.

12. Nurhayati, M. Laniwati dan Subagjo, Kinetika Dehidrasi N-butanol Pada Katalis Alumina Aktif, Prosiding Seminar Nasional Fundamental Dan Aplikasi Teknik Kimia, (Surabaya, 24-25 Nopember 1999), 1999.

13. S. Findik and G. Gunduz, Isomerization of $\alpha$-Pinena to Champene, JAOCS, 4(9):11451151), (1997).

14. F. S. Guner, Castor Oil Dehydration Kinetics, JAOCS, 74(4):409-412, (1997).

15. M. Sitorus. Spektroskopi Elusidasi Struktur Molekul Organik, Graha Ilmu Yogyakarta, 2009. 